\title{
Safety Impact of Distributed PV Random Access to the Grid Overhaul
}

\author{
Lin Qi-you \\ Wuhu Power Supply Company \\ Wuhu, China \\ njhniqy@sina.com
}

\begin{abstract}
PV as an important form of new energy, which has good prospects has been developed rapidly in recent years. However, distributed PV grid causes such as power quality, stability and reliability, also distribution Maintenance island effect will work to bring a lot of PV systems security risks. This mainly caused by random output characteristic of PV. Although the SGC issued 'the regulations on photovoltaic power station connected to the electricity grid technology' for the problems of photovoltaic power station connected to the grid, which is a preliminary stipulation for the safety defend of photovoltaic power station connecting to the grid, but there is not a security protection scheme specific to power grid maintenance work. In order to reduce the impact of distributed PV random access to the grid overhaul, it is necessary to set three security barriers. At the same time, to prevent isolated island effect, we need to use remote monitoring system to detect isolated island on the basis of a detailed analysis of the isolated island effect. Avoid isolated island effect on the operational safety and personal safety.
\end{abstract}

Keywords- Power system; distributed PV; power grid maintenance work; three security barriers; remote monitoring system.

\section{INTRODUCTION}

As an important part of distributed generation, PV has many advantages so that it has been widely promoted in the world, such as having abundant solar energy resources, with small pollution from production to use. However, the rapid development of distributed generation technologies presented by photovoltaic power plants, may cause structural changes in the power distribution network and take new demands in distribution system, especially in terms of safety, protection and maintenance ${ }^{[1-4]}$. Direction of power flow in distribution network will change significantly when PV power plant access to the distribution system, at the same time, short-circuit current level fault will also be changed, leading to significant changes in the distribution network, which will have a huge impact on the traditional distribution network protection, maintenance and other work. Therefore, in order to ensure an accurate security during grid fault repair work, it is necessary to study the impact of photovoltaic power plants distributed access to traditional distribution networks, then proposed with the maintenance and monitoring of photovoltaic power plants to meet the principles of grid access, finally eliminate the impact of distributed photovoltaic access to traditional distribution network overhaul and remove technical barriers of largescale photovoltaic power plants access to distribution network $^{[5-8]}$.

Distributed photovoltaic random access to grid will significantly affect the safe and stable operation, including voltage stability, protection, operational control, planning and design, Network Maintenance, economic and other aspects. This paper studies mainly on the impact of distributed PV safety net on the grid overhaul. The largest impact of distributed PV Grid is the overhaul may occur unplanned islanding. The reason of unplanned islanding is PV inverter is not disconnected after a short trip to the grid, PV systems continue to supply local load. If the PV inverter does not promptly disconnect, Re-jump line or connected equipment may be damaged due to the closing out of step ${ }^{\text {9]. }}$. During the isolated island, maintenance workers who consider that the line is not electrified grid will suffer from the security threats ${ }^{[10]}$. So, in order to avoid random access PV serious consequences on the grid overhaul, we must adopt the most effective method for islanding detection, preventing the occurrence of unplanned islanding. At the same time, the establishment of on-line monitoring system and remote decision systems can further improve the security of the power grid overhaul.

\section{THE IMPACT OF DISTRIBUTED PV RANDOM ACCESSING TO THE GRID OVERHAUL}

The biggest technical challenge of the development of photovoltaic is to achieve the anti-islanding. As more and more randomly distributed PV systems connected to the grid, endangering island effect becomes more prominent, the impact on the safety of the power grid overhaul become greater. Specific performance is:

(1)Re-jump line or connected device may be damaged due to the stall closing;

(2)Maintenance workers will be suffered from security threats during silos;

(3)Islands may interfere with normal power system operation manual or remote automatic reclosing islands under may affect the distribution system protection switch action program, leading the line again, tripping, destruction and inverter and connected equipment;

(4)Single-phase distributed grid system in the event an island, if not promptly disconnect may cause or exacerbate local unbalanced three-phase system, increasing the difficulty and workload grid overhaul. 
Most of distributed PV access to the grid at the user side self-occupied and connect the remaining power to the grid. During normal operation, distributed PV systems connected to the grid, the switch operate. When the line fails, substation supply-side switch tripped, at a time when anti-islanding protection of distributed PV function failure, the switch cannot be cut off or the network-side output balance the load in place, the isolated island effect will happen, which will bring security risks to electrical maintenance personnel.

As shown in Figure 1, according to Q/GDW480 $2010<$ Distributed power grid connection technology requirements>, Island effect refers QF1 switch off after a while, the common connection switch QF2 (or distributed $\mathrm{PV}$ access device) could not detect the isolated island and cut off the switch immediately, enables distributed PV systems still transport electricity to the grid. When the grid loss of power due to an accident or outage maintenance, if the distributed PV system output matches the local load the isolated island effect may occur, causing the line to be overhaul electrified(as shown by dashed line in Figure 1). This will bring security risk to the system equipment and related personnel.

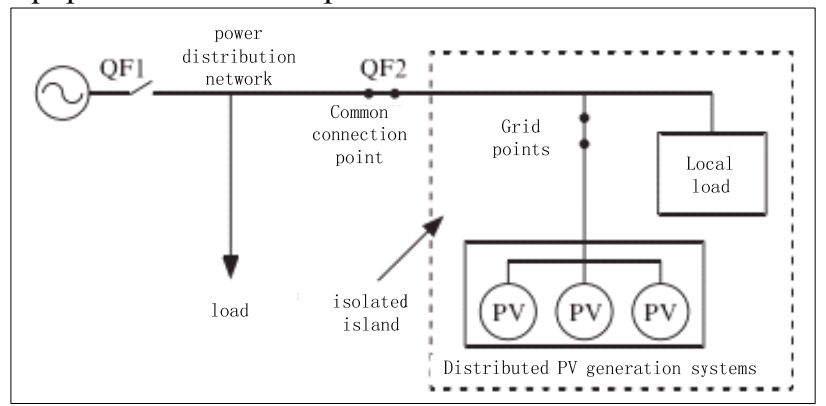

Figure 1. The signal of Islanding photovoltaic system

Distributed grid-connected photovoltaic power typical design shown in the following figure 2-5. Among them: A typical wiring Diagram of $10 \mathrm{kV}$ photovoltaic power accessing to distribution network is shown in Figure 2 (a), (b) below; Typical wiring $10 \mathrm{kV}$ PV power supply by internal users access to the distribution network in Figure 3 (a), (b) below; A typical wiring Diagram of $380 \mathrm{kV}$ photovoltaic power accessing to distribution network is shown in Figure 4 (a), (b) below; Typical wiring $220 / 380$ V PV power supply by internal users access to the distribution network in Figure 5 (a), (b) below;

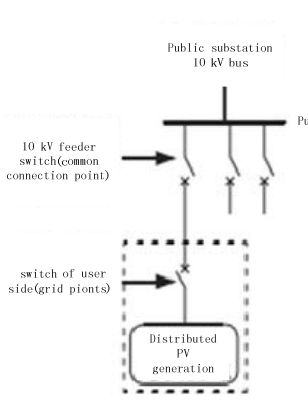

(a) Special access

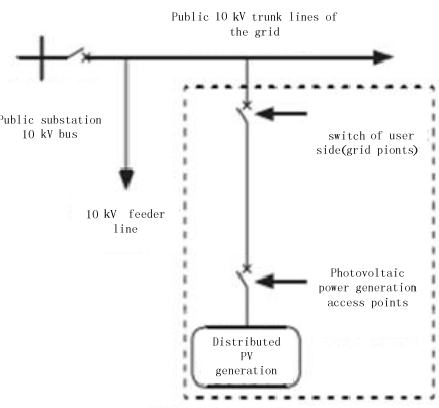

(b) $T$ access
Figure 2. $10 \mathrm{kV}$ PV typically access to the distribution network supply wiring

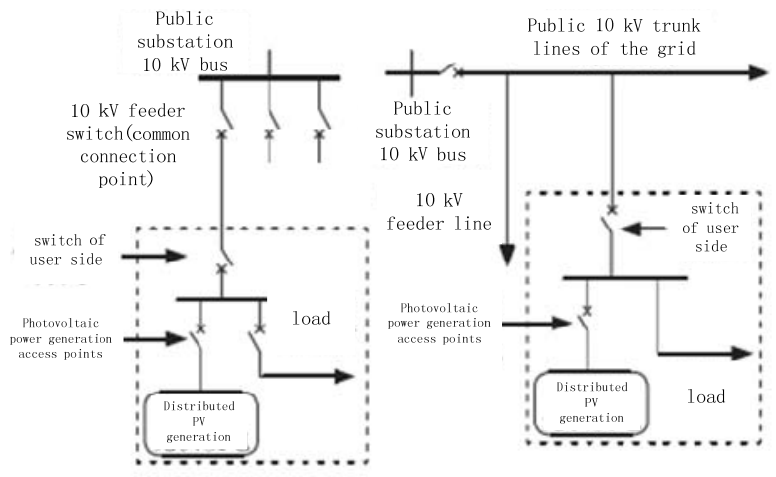

Figure 3. $10 \mathrm{kV} \mathrm{PV}$ power access to the internal distribution network wiring by user side

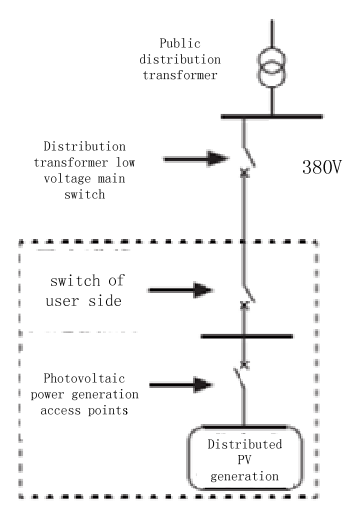

(a) Special access

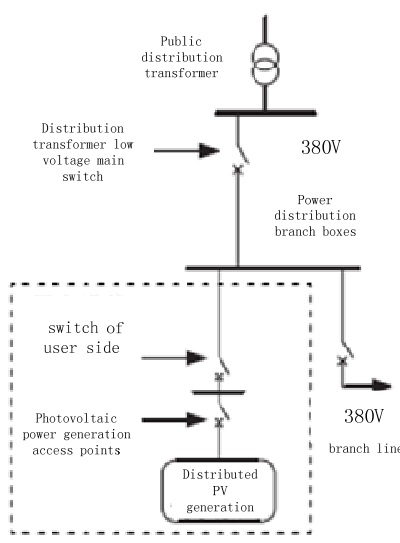

(b) $\mathrm{T}$ access
Figure 4. $380 \mathrm{~V}$ photovoltaic power typically access to the distribution network supply wiring

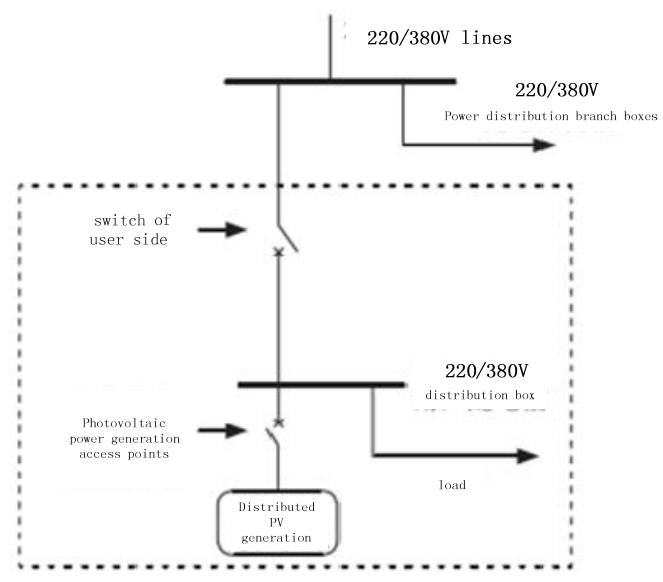

Figure 5. 220/380V PV power access to the internal distribution network wiring by user side

Effects of different access methods to overhaul security:

(1) For the distributed photovoltaic power using dedicated access to distribution network (as shown in Figure 2 (a), 3 (a), 4 (a)), during maintenance or repair work, disconnect the $10 \mathrm{kV}$ feeder switch (common connection point) directly or $380 \mathrm{~V}$ low voltage distribution network switch, so that we can ensure that the distributed grid-connected photovoltaic power supply and 
distribution network is disconnected, also the distributed photovoltaic power will not form an unplanned isolated island. Therefore, the use of dedicated access with distributed power grid-connected PV power does not pose a safety impact on the maintenance or repair operations.

(2) For distributed grid-connected photovoltaic power using the T-type access to the grid (as shown in Figure 2 (b), 3 (b), 4 (b), 5). After the public substation bus (distribution transformer low voltage main switch) is cut off, distributed grid-connected photovoltaic power and load balancing in situ which is likely to form an unplanned island operation and cause an impact on safety overhaul.

Given the impact of distributed PV on the distribution network, there is no one measure or technology to fully solve the security problem of distributed photovoltaic that requires systematic consideration of distributed photovoltaic grid security. Under the existing conditions, we should mainly follow two principles and the establishment of three security barrier.

\section{GRID ACCESS SETUP THREE SECURITY}

\section{BARRIER AFTER PHOTOVOLTAIC (PV) RANDOMLY}

\section{ACCESS}

\section{A. Setting principle of safety protection}

1. principle of security

Distributed photovoltaic (pv) grid first ensure the safety of power grid enterprises and users, no matter what method distributed photovoltaic using to access, no matter what is distributed photovoltaic running state, should be to ensure that the power grid, the equipment and personal safety.

\section{2. principle of economy}

Distributed photovoltaic grid should be satisfying the premise of security to minimize the power grid companies and the investment of users, so as to achieve the aim of supporting distributed photovoltaic grid power generation. Although through the way of increasing the investment in safety protection, configuring multiple protections and a large number of monitoring equipment, etc., Can effectively improve the safety of distributed photovoltaic power generation, but the investment cost of distributed photovoltaic are also increased significantly. At present, investment capital of the general distributed photovoltaic, which under the condition of no additional subsidies, is recovered in 10 years or so commonly, if add a lot of safety equipment investment cost again, the return period of the photovoltaic user investment would be return further extended, it is not conducive to the sustainable and healthy development of photovoltaic industry. So we still need to consider economy configuration principle in distributed photovoltaic grid security protection.

\section{B. Three security barrier of safety protection}

From the principle of safety, economy, under the existing conditions, it is available from these three aspects obtains: the PV inverter, interconnection switches, low voltage bus, to constitute effective safety protection system, as shown in figure 6 .

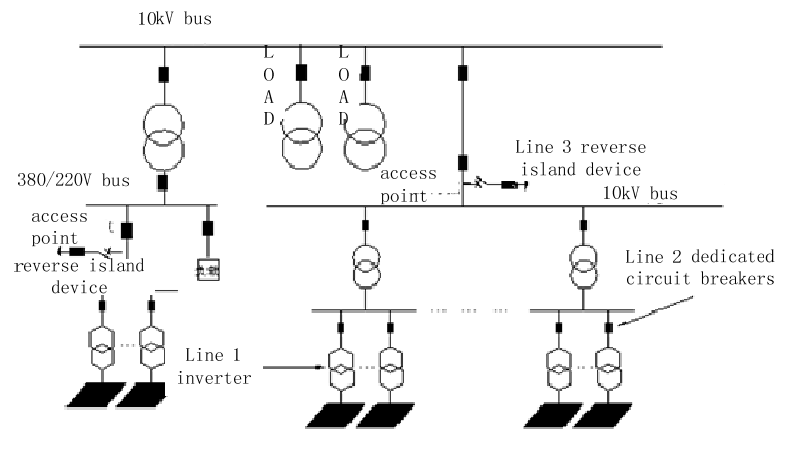

Figure 6. Schematic diagrams of safety protection three security barrier

(1) Barrier 1 -- inverter protection

Distributed photovoltaic inverter itself widely has the abnormal voltage, frequency response and the function of island protection, according to the requirements of $<$ the condition of special grid photovoltaic inverter technology $>$. Under the voltage of the inverter ac output exceeds the voltage range in table 1, inverter power supply shall be cut off to the grid, and issued a warning signal.

TABLE I. INVERTER VOLTAGE ABNORMAL RESPONSE TO A REQUEST

\begin{tabular}{c|c}
\hline The voltage of the inverter ac output & The biggest trip time $/ \mathbf{s}$ \\
\hline $\mathrm{V}<50 \% \mathrm{~V}$ nominal & 0.1 \\
\hline $50 \% \mathrm{~V}$ nominal $\leq \mathrm{V}<85 \% \mathrm{~V}$ nominal & 2.0 \\
\hline $110 \% \mathrm{~V}$ nominal $<\mathrm{V} \leq 135 \% \mathrm{~V}$ nominal & 2.0 \\
\hline $135 \% \mathrm{~V}$ nominal $<\mathrm{V}$ & 0.05 \\
\hline
\end{tabular}

At the change of rated frequency, working condition to the power grid frequency inverter should be meeting the requirements of the following table 2. As for inverter frequency response of the power grid, while the grid frequency back to allowing frequency of the grid, frequency inverter can restart.

TABLE II. ABNORMAL INVERTER FREQUENCY RESPONSE REQUIREMENTS

\begin{tabular}{c|c}
\hline $\begin{array}{c}\text { Range of } \\
\text { frequency } / \mathbf{H z}\end{array}$ & Time of the inverter to response \\
\hline $\mathrm{F}<48$ & Stop running within $0.2 \mathrm{~s}$ \\
\hline $48 \leq \mathrm{f} \leq 49.5$ & Stop running after running for $10 \mathrm{~min}$ \\
\hline $49.5<\mathrm{f} \leq 50.2$ & Running normally \\
\hline $50.2<\mathrm{f} \leq 50.5$ & $\begin{array}{c}\text { Stop running after running } 2 \text { min, at this point in a } \\
\text { suspended state inverter grid is not allowed }\end{array}$ \\
\hline $50.5<\mathrm{f}$ & $\begin{array}{c}\text { Stop supply power to the grid within } 0.2 \mathrm{~s} \text { at this } \\
\text { point in a suspended state inverter grid isn't allowed }\end{array}$ \\
\hline
\end{tabular}

Inverter's protection function for avoid island has made the interconnection technology standards in the world, such as UL1741, IEEE Std. 929 and IEEE Std. 1547 and so on, all provide power generation device, which is to grid-connected, must have island protection function, and design the specific prevention island protection test circuit and the test method. But, due to different demands of grid technology and distribution network operation, there is not a unified requirement on island protection configuration of distributed photovoltaic 
internationally, it is also different to the requirement of the island protection action time, inverter island technology performance reliability cannot be guaranteed. Detection DISPOWER to Germany in 2006 and used by the power grid impedance change of the island strategy and grid voltage and frequency of monitoring of photovoltaic power inverter was tested, the results show that when the power grid in the operation of the high impedance is not ideally, pv power inverter detection accuracy is poorer, grid impedance change possible user to reverse transmission power equipment, power generation equipment cause has electric power equipment, and imperil homework personnel safety. Due to the lack of national standard for inverter itself quality, distributed photovoltaic access to reduce the project cost, and users tend to choose low price of inverter, the inverter quality uncertainty, at the same time, the function of the inverter setting is usually does not consider interaction with the protection of power system, so you need to consider complementary protective measures.

(2) Barrier 2 - specialized in low voltage circuit breaker

Distributed photovoltaic access network dedicated circuit breaker have the function foe reliable shut off, at the same time, add new inspection without pressure trip function and check a switching function, can effectively cooperate with the superior power grid security automatic device. Check no pressure tripping dysfunctional tripping, recommend setting value $30 \%$ UN delay recommended 10 s. $30 \% \mathrm{UN}$ inspection without pressure setting value is to ensure that the system is permanent fault occurs, a distributed photovoltaic disconnect with the system correctly, into the network running status. Delay $10 \mathrm{~s}$ is greater than the local power system for the shoot, reclosing and action is the longest time, feeder automation ensures that temporary fault system (including the superior power supply for automatic switch, line fault overlap success, etc.) or when the voltage fluctuation, keep distributed photovoltaic generation $(\mathrm{dg})$ state waiting for system back to normal, improve the reliability of distributed photovoltaic power generation. Fixed value $30 \%$ UN recommend pressure switch and switch must be manual operation, to ensure normal operation of power generation equipment in the system to allow parallel operation, and to effectively prevent the electricity distribution equipment maintenance and user wrong operation to the system's power.

(3) Barrier 3 -- Reverse island device

Reverse island device is specially designed for electric power maintenance or related power operation personnel of a reverse island equipment, mainly composed of operating switches and load disturbance, which is based on photovoltaic power generation operation mechanism and the island protection strategy for development and design, through the destruction of distributed photovoltaic island operation conditions, to carry on the functions of the island. Reverse island device generally installed in the place where distributed photovoltaic system sends out the line grid side, in power personnel maintenance related to distributed photovoltaic route or the use of equipment. Disturbance, are formed by reverse island device to detect abnormal voltage or frequency inverter, ensure that within
$2 \mathrm{~s}$ protection action, achieve the goal of damage island operation.

Through three barrier set, under the condition of existing equipment, it can solve distributed photovoltaic system low voltage grid security issues. Because of distributed photovoltaic inverter, a dedicated circuit breaker itself exists in distributed photovoltaic access project, it just increased and adjustment on the equipment performance parameters, did not add new device, and special low pressure reverse island device is only in the distributed photovoltaic grid capacity reaches a certain proportion (such as the superior transformer rated capacity of $25 \%$ ), which is mean that, under the condition of forming islands, the installation can be configured, and the function of the device is simple and practical, cost price is low, on the base of systematically Solved the distributed photovoltaic low-voltage grid security, it is also well both in economy and reduce the engineering cost of users.

\section{ONLINE MONITORING OF PHOTOVOLTAIC ACCESS}

With China's implementation of distributed power grid incentives, distributed power grid is the future trend. However, the distributed power with discrete, volatility, intermittent characteristics makes its control ability, predictability is often lower than conventional power, which brings larger threat of safety and reliability when the distributed power access to grid. If you can't upload the operating status information to the monitoring center in a timely manner, the monitoring center can't send control commands quickly to distributed power too. For a large number of low voltage level distributed power, and also in remote areas, investment costs of the laying of power dedicated communication circuit is high ${ }^{[11-12]}$. This behind operation and management mode brings great difficulties to the monitoring center in management and control of distributed power. Moreover, many of the distributed power supplies are contracted by individual operators, such as solar power. There are many operators who install solar panels on their own roofs. When household electricity consumption is low during the day, those operators will feed the excess electricity fed into the grid. The operators of distributed power are not going to spend a lot of expense to establish complex linked communication system with the monitoring center. In order to meet the demand for distributed power real-time monitoring of the monitoring center, Based on GPRS network communication between the monitoring center and distributed power supply, not only can use the readymade communication network, and the investment cost is lower, information transmission is stable, reliable, fast and real-time. This is a good choice for both all kinds of distributed power supply operators and the monitoring center ${ }^{[13]}$.

It can be expected that, if we want to constitute the geographically widespread, a decentralized, distributed power supply to be a safe, intelligent, green energy scheduling management system, the study of distributed power supply remote monitoring technology is of great significance ${ }^{[14-15]}$. 
In the process of network maintenance, distributed power on-line monitoring system mainly complete the function for: System, combined with dispatch SCADA in dispatching monitors displayed on the monitor panel distributed power access point and the position of access lines, all the electric parameters and the access routes, before the repair work, scheduling controller based on distributed power online monitoring system of acquisition and back of the above information, to determine whether the line charged or maintenance condition, if not suitable for maintenance, the system will give alarm information and identify the name, the monitoring staff can inform the maintenance department of the current maintenance line charged, not for maintenance work, at the same time, also can through the system function of remote control, a control command, from the photovoltaic (PV) and network of GPRS DTU receives and compile remote message, control relay work, complete the circuit breaker control switch.

The operation process of this system as shown in the figure below:

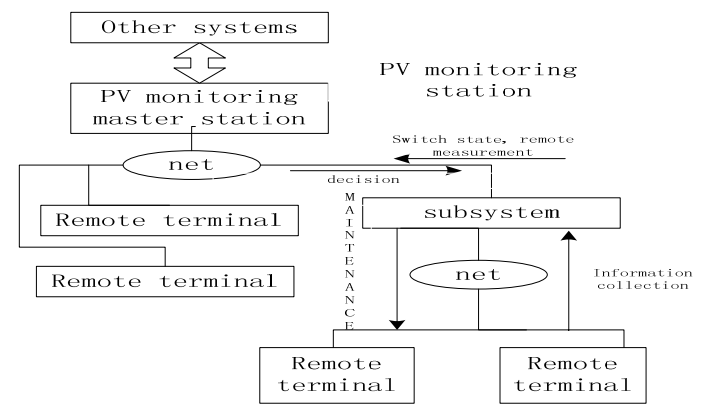

Figure 7. System operation flow chart

Distributed photovoltaic remote on-line monitoring system is the use of substation and the main works in harmony, DG side of switch state collected by substation and electric parameters $(\mathrm{P}, \mathrm{Q}, \mathrm{I})$ remote measurement and real-time transmission to the monitoring master station. Host the switch state and electrical remote measure in the grid side comprehensively, accurately judge whether there is a planned island. Either set of switch in DG side is on the switching state, or any set of electric parameters is not zero, the monitoring master station will prompt maintenance personnel for maintenance work, make sure the safety of power grid failure repair work. The process of the system is as shown in figure 8 .

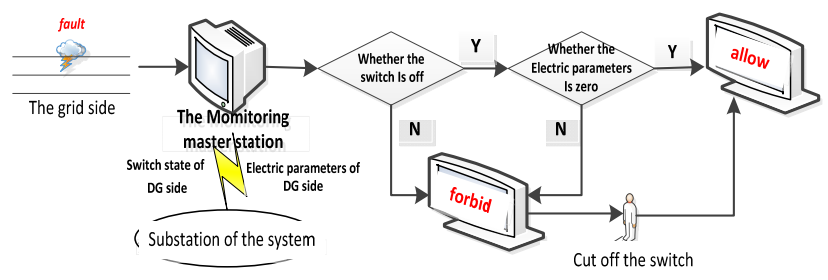

Figure 8. Flow chart of master station integrated system

\section{APPLICATION INSTANCE}

A project location for the user side grid photovoltaic power station, the power generation capacity is $0.87 \mathrm{MW}$. This power project, a total of 1 area, collect to a set of high voltage after stepping up to $10 \mathrm{kV}$ voltage, connected to the plant open and close the high-pressure $10 \mathrm{kV}$ bus bar through the cable. According to recommend access system relay protection scheme, operation mode, system configuration and 'The relay protection and safety automatic device technical regulations', the state grid corporation (Q/GDW617-2011) 'The provisions on photovoltaic power station connected to the electricity grid technology', proposed system relay protection and safety automatic devices is configured to:

1. $10 \mathrm{kV}$ line protection

According to the national grid company 'typical distributed power access system design’ ([2013] no. 333), When special line access user $10 \mathrm{kV}$ bus, $10 \mathrm{kV}$ line on the user side configuration 1 set of line over-current protection and distance protection, the side of photovoltaic power station cannot configure line protection, rely on the user side to remove line fault.

As a result, can configure a set of line over-current protection in the point where the user's $10 \mathrm{kV}$ bus bar access. Current instantaneous fault protection is the main protection, overcurrent protection is backup protection.

2. $10 \mathrm{kV}$ bus protection

Users $10 \mathrm{kV}$ buses don't need to configure the busbar protection.

3. Line fault wave record

According to the state grid corporation of 'photovoltaic power station connected to the electricity grid technical regulations' (2011 edition), the relevant provisions are: "large photovoltaic power stations should be installed special fault wave record device." This project adopts the $10 \mathrm{kV}$ access systems, is a medium-sized photovoltaic power station, do not need to configure special fault wave record.

4. Security automatic device

According to the state grid corporation of 'photovoltaic power station connected to the electricity grid technical regulations' (2011 edition), the relevant provisions are: 'Large and medium-sized PV power station should be based on the instructions of the electric power dispatching department quickly control the output of active power, When necessary, can automatically by the safety automatic device quickly reduce active power photovoltaic power station or removal of photovoltaic power station. Accident treatment finished, return to normal operation of the power systems, photovoltaic power station shall be in accordance with the electric power dispatching department instruction in parallel operation'.

\section{Substation system side}

The Mountain Tianmen at the $10 \mathrm{kV}$ Tianbao 115 line access variable $10 \mathrm{kV}$ bus, configured line quick break, over current, reclosing protection. Don't need to add the line relay protection. Action request line reclosing time need to evade security automatic device.

Because of the current of photovoltaic power station to the side of the system is very small, estimates of about 75.3 A. As a result, after access photovoltaic power station, the substation system can ignore the influence of 
lateral $10 \mathrm{kV}$ bus, meeting the requirements of the photovoltaic power station access scheme.

6. Requirements for other professional

1) For the electrical professional at a time. System of relay protection should be used for secondary winding of current transformer and voltage transformer, current transformer accuracy level appropriate USES $5 \mathrm{p}, 10 \mathrm{p}$ level, voltage transformer accurate level appropriate USES 0.5, 3 p level.

2) Requirements for communications professional. System relay protection and safety automatic devices required to provide sufficient and reliable signal transmission channel.

3) Photovoltaic power station should have the dc power supply and UPS power supply, domestic demand for the new configuration of protection, measurement and control device, power quality online monitoring device equipment use.

\section{ACKNOWLEDGMENT}

In order to reduce the effects of distributed photovoltaic random access maintenance of power grids, this paper concluded as follows:

1. For the $\mathrm{T}$ distribution network access to the distributed grid photovoltaic power supply, after the public substation bus (with low voltage main switch changeable) disconnecting, distributed grid photovoltaic power and on-site load are balance, it is possible to not formed the island operation, effect the safety of maintenance. And use special line access grid photovoltaic power does not produce the above problems;

2. Distributed photovoltaic security access should be set three security barrier: The protection of inverter, specialized in low voltage circuit breaker and reverse island device;

3. In order to ensure the photovoltaic (PV) grid access security after the random access, we should configure distributed photovoltaic (PV) online monitoring system, to form a secure, intelligent, green energy scheduling management system, to study of distributed power supply remote monitoring technology is of great significance.

\section{REFERENCES}

[1] Zhu Yi-hua. Research Distribution Maintenance mode containing photovoltaic power plants [J]. Technology Information, 2012, (36): 124-125.

[2] Yang Lei.Distributed PV and low voltage network anti-islanding technology research and application of [D]. Nanjing Normal University, 2014.

[3] Ma Zhou-jun. Power system containing uncertain power flexible production simulation and evaluation research [J]. Journal of Shanghai jiaotong university, 2013.

[4] Feng Wei, Lin Hai-tao, Zhang Yu. Low voltage distribution network design principles and anti-islanding device parameter calculation [J] .Electric Power Systems, 2014, (2): 85-90.

[5] Chen Wei, Ai Xin, Wu Tao. Grid-connected PV systems on the grid impact studies review [J]. Electric Power Automation Equipment, 2014, (23): 26-32.

[6] Ding Ming, Wang Wei-sheng, Wang Xiu-li. Large scale photovoltaic effect on power system review [J]. Proceedings of the csee, 2014, (1). DOI: 10.13334/0258-8013. J. pcsee. 2014.01.001.

[7] Liu Jie, Yuan Songzhen, Yang Hai-zhu. Distributed PV systems on the grid and the Countermeasures [J] Telecom Power Technologies, 2013, 30 (2): 41-43.

[8] Kang Hai-yun, Kang Nai-shan, Lu Qiao. Distributed photovoltaic effect in the smart grid [J]. Power System and Clean Energy, 2013, (10): 86-90.

[9] Zhang Yue-chao, Liang Bing. Grid-connected photovoltaic systems and the impact of the distribution network of production safety management countermeasures [C]. virtual operator and cloud computing_The National Youth Communication Academic Conference 2013.

[10] Wang Hong-yan, Tian Rui-min, Qin Hui-min. Discussion of the state of the power system maintenance technology and management $[\mathrm{J}]$.Science and Technology Innovation Herald, 2013, (27): $71-71$

[11] Li Ling, Wang Huan-huan, Xie Li-li. Distributed Power Grid Monitoring System based on distributed Control [J]. Computer Measurement and control, 2010, 18 (3): 580-582.

[12] Wang Bing, Xu Jian-ming. Design and implementation of the remote distributed electrical source equipment monitoring and control system on internet [J]. Computer Engineering and Design, 2002, 23 (7): 32-35.

[13] Xu Jian-wei, Xu Guo-qing. Distributed power control system based on Labview [J]. Mechatronics, 2008, 14 (2): 59-68.

[14] Yu Lei. Design of a Supervise System for the Distributed Power Supply System Based on DSP and CAN Bus [J]. Nanjing University of Aeronautics and Astronautics, 2006.

[15] Zhang Tie-feng, Miao Hui-peng, Xin Hong-wang, Gu Jian-wei. Design of PV Monitoring System Based on IEC 61850 [J]. Electric Power Information and Communication Technology, 2014, 1(12): 60-64. 